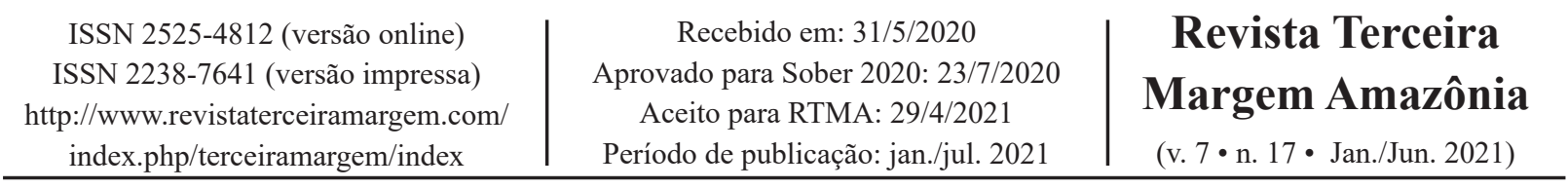

Como citar o artigo:

BRUM, C. P.; DEPONTI, C. M.; MENGEL, A. A. Compreendendo a dinâmica de produção de soluções tecnológicas pela agricultura familiar. Revista Terceira Margem Amazônia, v. 7, n. 17, p. 225-241, 2021. DOI: http://dx.doi.org/10.36882/2525-4812. 2021v7i17.p225-241

\title{
COMPREENDENDO A DINÂMICA DE PRODUÇÃO DE SOLUÇÕES TECNOLÓGICAS PELA AGRICULTURA FAMILIAR
}

\author{
Camila Pereira Brum ${ }^{1}$ \\ Cidonea Machado Deponti ${ }^{2}$ \\ Alex Alexandre Mengel ${ }^{3}$
}

\begin{abstract}
Resumo: Este artigo refere-se ao Projeto O Papel dos Agricultores Familiares na Produção de Soluções Tecnológicas para a Agricultura Familiar, realizado em parceria entre a Universidade Federal do Rio Grande do Sul (UFRGS)/Litoral Norte e a Universidade de Santa Cruz do Sul (Unisc), RS. A área da pesquisa é a região do Vale do Rio Pardo, RS. Para realização da pesquisa mobilizou-se um grupo de instituições importantes para a região e foi aplicado um formulário para a localização das soluções tecnológicas. Após a sistematização dos dados foram encontradas 58 técnicas e tecnologias geradas pelos agricultores. Posteriormente foram selecionados 18 casos considerados mais significativos para a equipe do projeto, para que fossem aplicados às entrevistas semiestruturadas. As entrevistas foram analisadas, e os resultados obtidos permitiram catalogar as soluções tecnológicas, com isso concluiu-se que os agricultores familiares encontram formas de resiliência e de manutenção no meio rural, além de produzirem conhecimentos traduzidos em produtos, processos ou práticas.
\end{abstract}

Palavras-chave: desenvolvimento regional, agência humana, agricultura familiar.

\section{UNDERSTANDING THE DYNAMICS OF PRODUCTION OF TECHNOLOGICAL SOLUTIONS BY FAMILY AGRICULTURE}

\footnotetext{
Abstract: This article refers to the Project called "The role of family farmers in the production of technological solutions for family farming", carried out in partnership between UFRGS - Litoral Norte and UNISC-RS. The research area is the Vale do Rio Pardo-RS region. To carry out the research a group of important institutions for the region was mobilized, and a form was applied to locate the technological

1 Bolsista da Universidade de Santa Cruz do Sul (Unisc), Santa Cruz do Sul, RS.

E-mail: millabrum99@gmail.com

(iD https://orcid.org/0000-0001-9716-8851

2 Economista, mestre em Integração Latino-Americana, professora da Universidade de Santa Cruz do Sul (Unisc), Santa Cruz do Sul, RS.

E-mail: cidonea@unisc.br

(D) https://orcid.org/0000-0001-8833-1450

3 Engenheiro-agrônomo, doutor em Ciências Sociais em Desenvolvimento, Agricultura e Sociedade, professor da Universidade Federal do Rio Grande do Sul (UFRGS), Tramandaí, RS.

E-mail: alexandremengel@gmail.com

(D) https://orcid.org/0000-0002-5470-4922
} 
solutions. After systematizing the data, 58 techniques and technologies generated by farmers were found. Subsequently, 18 cases considered most significant to the project team were selected for semi-structured interviews. The interviews were analyzed and the results made it possible to catalog the technological solutions. Thus, it was concluded that family farmers find forms of resilience and maintenance in the rural environment, besides producing knowledge translated into products, processes or practices. .

Keywords: regional development, human agency, family agriculture.

\section{Introdução}

Durante a década de 1950, com o objetivo de promover um maior desenvolvimento do setor agrícola, surgiu o processo de modernização da agricultura, "paradigma sob o qual a atividade inovativa foi institucionalizada na agricultura do Brasil e de outros países da América Latina" (OLIVEIRA, 2011, p.91). Seu desenvolvimento ocorreu por meio de um conjunto de instrumentos e de políticas públicas que atuaram como modernizantes no setor, ficando depois amplamente conhecidos no contexto mundial, em 1970, como Revolução Verde, que trouxe consigo, em sua verticalidade imposta pelos pacotes tecnológicos, a necessidade de reação e de adaptação dos agricultores perante as adversidades resultantes do processo, para que assim mantivessem sua permanência e manutenção no campo.

De maneira geral, pode-se afirmar que o paradigma da modernização agrícola dominou e ainda domina setores com política e práticas relacionadas à agricultura no meio rural (PLOEG et $a l ., 2004)$. Sua aplicação concebeu-se por meio da utilização do conceito de inovação no qual é tida como um processo evolutivo, que necessita de modificação para que assim seja incorporado como uma nova forma de organização do trabalho que resulta na melhoria de produtos e de processos já existentes (DEPONTI, 2019), obedecendo a um padrão linear de produção e de uso. A inovação não é apenas resultado da introdução de tecnologias ou de conhecimentos exógenos, as transformações na agricultura foram fortemente influenciadas por questões que tinham como objetivo a produção em massa, principalmente de alimentos, de forma crescente e com um rápido retorno do capital investido na produção.

Os agricultores familiares resistiram e vêm resistindo a um cenário extremamente adverso, desde o começo de sua história, no qual não são tidos como prioridade em políticas públicas relacionadas à atividade agrícola e que claramente beneficiam os grandes proprietários rurais que possuem um alto poder aquisitivo. Essa necessidade de adaptação dos agricultores familiares aqui é reconhecida como soluções tecnológicas, que são novas técnicas e tecnologias que, ao serem desenvolvidas e inseridas no processo produtivo, modificam a maneira que os agricultores familiares se relacionam com a natureza, ou seja, alterando sua forma de trabalhar e de viver. Compreender a inoperância do conceito de inovação, quando aplicado à realidade dos agricultores familiares do Vale do Rio Pardo, é fundamental para entender a região e principalmente a categoria como um todo.

O presente artigo faz parte do projeto de pesquisa intitulado Análise do Papel dos Agricultores Familiares na Produção de Soluções Tecnológicas para a Agricultura Familiar, financiado pelo Edital Universal do CNPq no ano de 2016, cujo objetivo é compreender como os agricultores familiares contribuem para a geração de novos processos, produtos, técnicas e tecnologias para 
a agricultura. Para isso faz-se necessário compreender a importância dos agricultores como categoria, analisando as soluções tecnológicas produzidas para suprir as demandas tecnológicas existentes em suas propriedades, fazendo com que seja possível a melhora na eficiência do que é produzido por eles em suas atividades agrícolas.

O artigo está dividido em cinco seções. Na primeira seção temos a introdução, em que o contexto da pesquisa será apresentado inicialmente. A segunda seção contém a fundamentação teórica da pesquisa, trabalhando principalmente com os conceitos de inovação e de soluções tecnológicas, em segundo plano analisando o conceito de produção de novidades e sua validade para o contexto no qual a pesquisa está inserida e sua relação com os outros conceitos já citados. $\mathrm{Na}$ terceira seção tem-se o detalhamento em relação à metodologia utilizada no projeto e sua aplicação. A penúltima seção aborda diretamente as soluções tecnológicas encontradas no Vale do Rio Pardo, analisando algumas das soluções selecionadas. Na quinta e última seção apresentam-se as conclusões do artigo.

\section{Fundamentação teórica}

Nesta seção serão trabalhados os conceitos de inovação, de produção de novidades e de solução tecnológica. Esses conceitos se aproximam e se afastam de acordo com a realidade estudada. No caso em análise, o objetivo desta seção é a compreensão do conceito de solução tecnológica que dê conta da realidade dos agricultores familiares.

\section{Teoria da Inovação}

Para Schumpeter (1982), considerado o pai da inovação, esta se caracteriza como um processo evolutivo, tendo como principal objetivo a geração de riqueza. Para isso é necessário que exista uma alteração nos métodos de produção, incorporando não só novas funções, como uma nova forma de organização de trabalho, resultando em novos produtos/processos ou na melhoria de produtos já existentes no mercado. Para que uma inovação, de fato, ocorra é necessário obedecer à "trilogia schumpeteriana" (STONEMAN, 1995), caracterizada por: invenção, inovação e difusão. Iniciando-se pela invenção de algo que possua potencial para gerar impacto; em segundo lugar é preciso que a ideia seja materializada em novos produtos ou processo com potencial para introdução no mercado; por último, o processo de inovação finaliza com a introdução, difusão e adoção de inovações por parte dos mercados potenciais (FERGUSON, 1988; STONEMAN, 1995).

$\mathrm{Na}$ operacionalização do processo de inovação tem-se o que é denominado de "modelo linear de inovação", no qual existe a divisão nítida de funções, cientistas especializados na geração de inovações, técnicos responsáveis pela transferência dos produtos resultantes do processo e agricultores que eram tidos como meros aplicadores da inovação (OLIVEIRA, 2011). Contudo, o que se observou na prática foi que muitas inovações aconteciam sem a interferência dos cientistas, em que os técnicos assumiram um papel de troca de informações entre os agricultores e os cientistas (SCHNEIDER, 2014). A partir disso, entendeu-se a presença e a importância que os agricultores têm na aplicação das inovações, não sendo o agricultor um mero receptor das tecnologias exógenas, como se pensou anteriormente. 
Embora o conceito amplo de inovação - qualquer coisa feita de forma diferente que possui efeito na vida econômica (SCHUMPETER, 1982) - admita grande flexibilidade, a tentativa de descrever a ocorrência da trilogia schumpeteriana (STONEMAN, 1995) e suas consequentes descontinuidades em mercado e tecnologia nos níveis micro e macro (GARCIA; CALANTONE, 2002) não acontece com a mesma facilidade. As ideias de incremento tecnológico e extensão da difusão tornam difícil aplicar o conceito de inovação ao meio rural.

\section{Inovação na Agricultura}

Os agricultores são reconhecidos como sujeitos portadores de agência, que é a capacidade de intervir em eventos, não necessariamente de modo intencional. Long (2007) evidencia que essa habilidade de influenciar a ação dos outros depende diretamente da existência e da criação de redes de relação com atores relevantes ou que possam mobilizar e envolver colaboradores em alguma tentativa de alcançar fins comuns ou que ao menos sejam compatíveis. Um agente deixa de o ser quando perde a capacidade de "criar uma diferença", que é exercer alguma espécie de poder.

Tratando de concepções existentes sobre a capacidade de agência dos agricultores, um trecho a se destacar é:

[...] Por essa noção os agricultores são dotados de uma ação ativa na construção de suas estratégias de desenvolvimento e dos seus projetos de vida. Eles possuem conhecimento e sabem como agir frente a um evento social mesmo não esperado, a ação das instituições ou de outros atores sociais com quem mantém interações de diversos tipos (KIYOTA et al., 2014, p. 74).

Não pode o agricultor ser considerado, no decorrer de toda a sua história, um sujeito passivo de sua realidade, sendo ele plenamente capaz de lutar por seu espaço e de resistir elaborando estratégias e adaptando-se do seu jeito a uma agricultura cada vez mais tecnológica, sem deixar de ser agricultor. Entender como resistem torna-se fundamental, e isso é traduzido pela geração de novos conhecimentos, técnicas, tecnologias ou produtos que aqui são reconhecidos como soluções tecnológicas.

Na conceituação realizada pelo Banco Nacional do Desenvolvimento (BNDES), soluções tecnológicas são caracterizadas como a aplicação de uma tecnologia ou know-how com o objetivo de aperfeiçoamento ou melhoria de produto ou processo em sua produção (BNDES, 2018). Prosseguindo o que é sugerido pelo BNDES, uma solução tecnológica, não a sua tecnologia em si, mas a sua aplicação (DEPONTI, 2019). A compreensão de solução tecnológica por parte do BNDES difere daquela utilizada neste artigo. Aqui a solução tecnológica é entendida como novas técnicas ou tecnologias que, ao serem desenvolvidas e inseridas no processo produtivo, modificam a maneira como os agricultores se relacionam com a natureza, ou seja, que transformam sua maneira de trabalhar e de viver. Na visão do BNDES, a solução tecnológica é algo vinculado à pesquisa científica. Neste artigo a compreensão de solução tecnológica está relacionada a algo criado e desenvolvido pelos agricultores no seu cotidiano.

Além desses conceitos, há na literatura o conceito de produção de novidades. Para se entender as diferenças entre solução tecnológica e produção de novidades primeiro é necessário 
compreender conceitualmente cada um deles. Oliveira e Araújo (2014) considera a produção de novidades como um processo contínuo de solução de problemas diários e de criação de novas e melhores maneiras de aperfeiçoar o uso dos fatores de produção e de praticar a agricultura, que tem como base as práticas e os saberes locais e a integração de conhecimentos científicos com conhecimentos tradicionais.

As principais diferenças entre os conceitos de solução tecnológica e produção de novidades é o de que, enquanto na produção de novidades, os atores locais, além de fazerem resistência frente ao sistema e terem plena consciência do seu papel, eles estão em um processo de transição sociotécnica de produção, em geral diretamente relacionado à agroecologia e ao paradigma de desenvolvimento rural. Neste o conceito de transição pode ser entendido como um processo gradual e contínuo de mudanças em que ocorre a transformação de uma sociedade (OLIVEIRA; ARAÚJO, 2014). A solução tecnológica, por sua vez, tem como objetivo garantir a permanência do agricultor no processo produtivo ao qual ele está inserido, possibilitando sua manutenção e sobrevivência no contexto rural.

Ambos os conceitos se assemelham muito, havendo a necessidade de, no decorrer da pesquisa, fazer uma escolha entre os dois. Em função do contexto regional dos agricultores familiares do Vale do Rio Pardo, marcado não só pela dependência econômica dos municípios na produção de tabaco que, por sua vez, representa $61,5 \%$ do valor bruto da produção agrícola, tornando-o uma monocultura na região (AREND et al., 2019), como também por possuir propriedades com tamanho médio de 18 ha, dificultando o desenvolvimento de outras culturas, optou-se pelo conceito de solução tecnológica. Esses fatores contribuíram para que o conceito de soluções tecnológicas fosse o que melhor se adaptasse à realidade regional existente entre os agricultores familiares que objetivam sua manutenção, e não uma transição de sua atividade agrícola atual para a agroecologia, por exemplo.

\section{Metodologia}

A realização da pesquisa aconteceu em razão de uma parceria entre a UFRGS - Campus Litoral Norte, e a Unisc, em que foi selecionado como área de atuação da pesquisa o Conselho Regional de Desenvolvimento (Corede) ${ }^{4}$ do Vale do Rio Pardo, que atualmente é composto por 23 municípios. Sua escolha deve-se principalmente à importância da agricultura familiar no contexto regional do Vale do Rio Pardo, em que, segundo Karnopp (2012), cerca de 40\% da população reside e trabalha no campo, possuindo pequenos estabelecimentos familiares em média com 18 ha de extensão.

A metodologia utilizada para a pesquisa teve como foco a participação direta dos atores locais, por causa principalmente da dispersão geográfica dos agricultores familiares no território do Vale do Rio Pardo, o que acabou dificultando tanto a identificação como a localização deles. Para a realização da pesquisa foi construída uma ampla rede de colaboradores, a saber: Escola Família Agrícola de Santa Cruz do Sul (Efasc), Associação dos Fumicultores do Brasil (Afubra), Arranjo Produtivo Local (APL) e a Empresa de Assistência Técnica e Extensão Rural (Emater). Essas

\footnotetext{
4 O Corede do Vale do Rio Pardo, criado em 1991, é parte integrante dos 28 Conselhos Regionais de Desenvolvimento do Rio Grande do Sul, cujo papel é promover ações e políticas que visem ao desenvolvimento da região.
} 
instituições parceiras ficaram responsáveis por aplicar o formulário para possibilitar a localização das soluções, que ocorreu no período entre 2016 e 2017 (MENGEL et al., 2020), principalmente devido aos seus conhecimentos sobre a realidade da agricultura familiar regional e a sua maior proximidade com os atores locais pesquisados.

Figura 1. Mapa de localização do Conselho Regional de Desenvolvimento do Vale do Rio Pardo, RS.

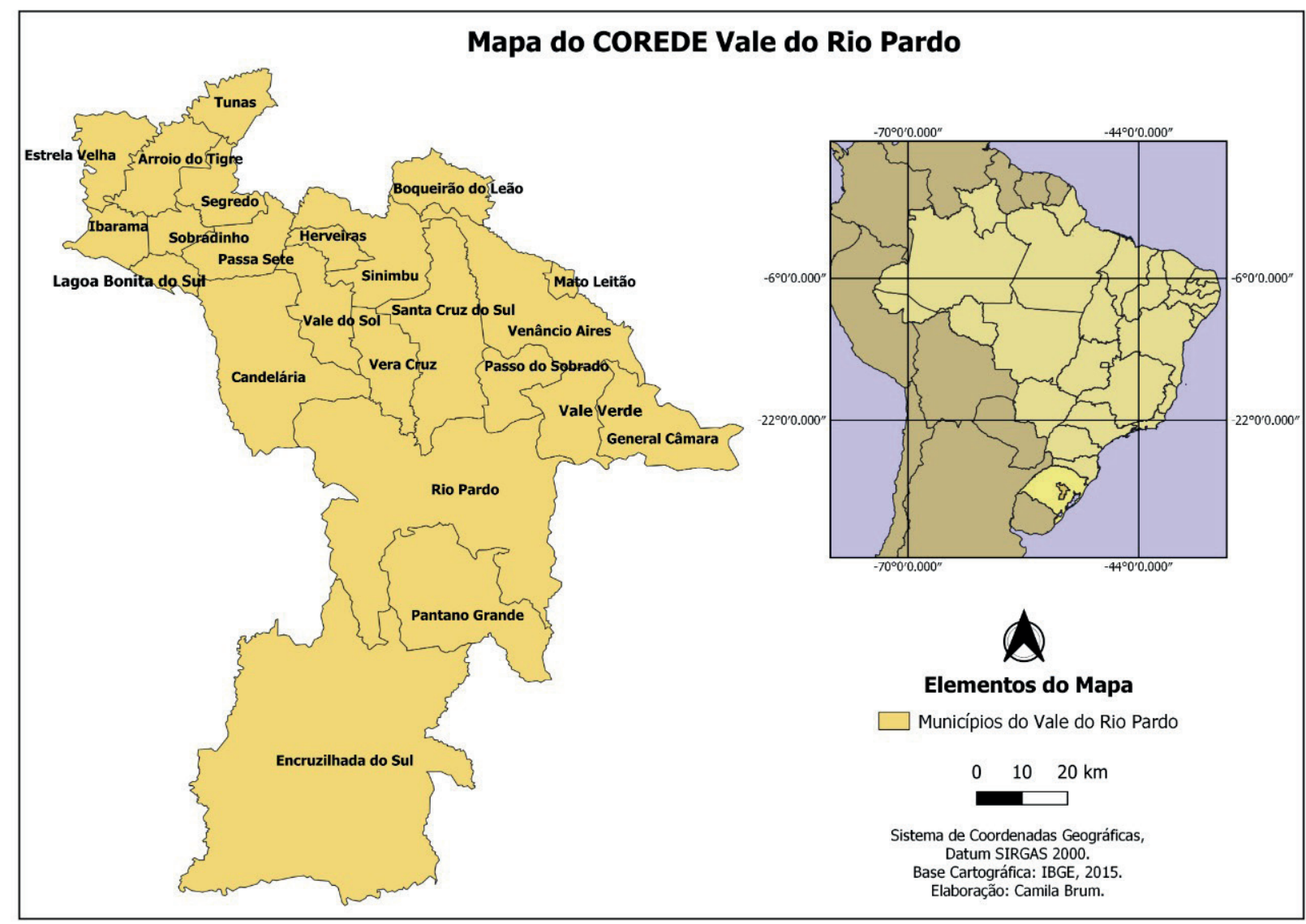

Forte: Equipe de pesquisa

Esse formulário foi construído de uma forma simples e que possibilitasse ao agricultor o tempo necessário para que as perguntas fossem respondidas de modo eficiente, para que a pesquisa prosseguisse da melhor forma possível, sendo entregue aos agricultores pelos técnicos que realizam usualmente visitas a propriedades rurais. Ele foi constituído por nove perguntas: 1) nome do criador; 2) contato; 3 ) município; 4) solução tecnológica desenvolvida; 5) atividade produtiva; 6) problema existente; 7) função da solução; 8) número de agricultores que utiliza essa solução; 9) se existe solução semelhante no mercado. A aplicação foi realizada a partir de outubro de 2016 e seguiu até março de 2017, quando os resultados foram recolhidos pelos técnicos das instituições participantes do projeto.

Depois dos dados devidamente coletados e repassados para os responsáveis pelo projeto, que juntamente com a equipe montada para a pesquisa analisou detalhadamente cada um dos casos, foram sistematizados, encontrando-se 58 técnicas, tecnologias, processos e produtos que 
foram desenvolvidos pelos agricultores familiares do Vale do Rio Pardo. Depois foram selecionados 18 casos, que receberam uma visita para a aplicação das entrevistas semiestruturadas abordando-se as principais questões, a saber: 1) o que foi criado? 2) qual sua função? 3) existe algo similar no mercado ou processo parecido? 4) caso exista, qual a razão de ter sido criado? 5) como ocorreu o processo de criação? 6) quais as transformações que tal solução criada produziu no cotidiano da família? As entrevistas semiestruturadas ocorreram nos meses de novembro e dezembro de 2017 e fevereiro de 2018.

A colaboração existente entre as instituições participantes do projeto tornou-se parte fundamental para a obtenção dos resultados necessários para o desenvolvimento e compreensão da importância da pesquisa. Os 18 casos selecionados para a aplicação das entrevistas semiestruturadas encontram-se nos municípios de Arroio do Tigre, Ibarama, Santa Cruz do Sul, Sinimbu e Sobradinho, todos pertencentes ao Corede do Vale do Rio Pardo.

\section{Resultados e Discussão}

Com a utilização da metodologia citada anteriormente, encontraram-se 58 técnicas, tecnologias ou produtos gerados pelos agricultores do Vale do Rio Pardo. Posteriormente, foram selecionados 18 casos para o recebimento das entrevistas semiestruturadas. Esse procedimento foi realizado pela equipe do projeto, que depois de analisar detalhadamente as 58 técnicas, tecnologias ou produtos identificaram que, dentre todos os casos, apenas 18 melhor caracterizavam-se como soluções tecnológicas e que mais se aproximavam do conceito de solução tecnológica utilizado pela pesquisa, evidenciando essa nova forma de saber fazer. Os outros 40 casos se assemelhavam muito mais aos conceitos de inovação e de produção de novidades. Pretende-se reunir os 58 casos e disponibilizá-los posteriormente no site da pesquisa ${ }^{5}$.

Dentre as soluções tecnológicas encontradas no Vale do Rio Pardo, serão analisadas, no quadro a seguir, quatro soluções: a enxada vazada, o limpador de feijão, a plantadeira de fumo adaptada e o disco adaptado com rodas e regulagem de profundidade. Posteriormente, será realizado o detalhamento de cada uma das soluções tecnológicas selecionadas e o contexto no qual elas estão inseridas. Essas soluções tecnológicas ${ }^{6}$ (Tabela 1) estão localizadas nos municípios de Arroio do Tigre, Santa Cruz do Sul e Sobradinho e evidenciam a capacidade existente entre os agricultores familiares de gerarem técnicas, tecnologias ou produtos com eficiência e que melhor se adaptam à realidade de suas pequenas propriedades.

No processo de geração de uma solução tecnológica nota-se que ele acompanha as próprias características existentes na atividade agrícola. Pinto (2005) define a tecnologia como a reflexão sobre a técnica dominada, materializada em um instrumento, método, produto. A reflexão sobre a técnica, na agricultura, depende especialmente de seus ciclos biológicos, interagindo diretamente com a vida, pois o novo instrumento ou método deve se adequar às diferentes características das plantas ou animais a que ele se destina.

\footnotetext{
5 As soluções tecnológicas encontradas durante a pesquisa estão disponibilizadas no site do projeto: htttp://www.ufrgs.br/ observatoriosolucoesaf/

6 Tendo em vista as orientações da Resolução n 510, de 7 de abril de 2016, do Conselho Nacional de Saúde, no momento de realização das entrevistas, o consentimento dos entrevistados que participaram da pesquisa foi coletado e gravado.
} 
Tabela 1. Soluções tecnológicas dos municípios de Arroio do Tigre, Santa Cruz do Sul e Sobradinho, Rio Grande do Sul, Brasil.

\begin{tabular}{|c|c|c|c|c|c|}
\hline Criador & $\begin{array}{l}\text { Atividade } \\
\text { produtiva }\end{array}$ & Problema existente & Solução gerada & Benefício gerado & $\begin{array}{l}\text { Solução } \\
\text { existente no } \\
\text { mercado }\end{array}$ \\
\hline A.K & $\begin{array}{l}\text { Eletricista/ } \\
\text { ferreiro/ } \\
\text { fumicultor }\end{array}$ & $\begin{array}{l}\text { A limpeza da lavoura } \\
\text { utilizando a enxada } \\
\text { disponibilizada no } \\
\text { mercado tornava } \\
\text { o trabalho muito } \\
\text { desgastante, devido ao } \\
\text { peso e à necessidade } \\
\text { de realizar movimentos } \\
\text { repetitivos }\end{array}$ & Enxada vazada & $\begin{array}{l}\text { Diminuição da } \\
\text { penosidade do trabalho } \\
\text { de remoção do inço nas } \\
\text { lavouras }\end{array}$ & Não \\
\hline N.B & $\begin{array}{l}\text { Cultivo de } \\
\text { grãos }\end{array}$ & $\begin{array}{l}\text { A necessidade de } \\
\text { reduzir o tempo gasto } \\
\text { para limpar o feijão e a } \\
\text { necessidade de mão de } \\
\text { obra para a realização } \\
\text { da limpeza no modelo } \\
\text { manual }\end{array}$ & $\begin{array}{l}\text { Limpador de } \\
\text { feijão }\end{array}$ & $\begin{array}{l}\text { A qualidade do feijão } \\
\text { melhorou e a mão de obra } \\
\text { foi reduzida }\end{array}$ & Sim \\
\hline R.Q & Fumicultor & $\begin{array}{l}\text { O bico da máquina } \\
\text { convencional, além de } \\
\text { menos resistente, faz } \\
\text { com que a muda tenha } \\
\text { dificuldades para sair da } \\
\text { máquina. A falta de um } \\
\text { marcador de distância } \\
\text { entre uma planta e } \\
\text { outra prejudicava o seu } \\
\text { desenvolvimento }\end{array}$ & $\begin{array}{l}\text { Régua que } \\
\text { marca a } \\
\text { distância } \\
\text { acoplada à } \\
\text { plantadeira de } \\
\text { fumo adaptada }\end{array}$ & $\begin{array}{l}\text { A modificação } \\
\text { possibilitou o aumento } \\
\text { da vida útil da máquina, } \\
\text { além de fazer com que } \\
\text { a planta ficasse mais } \\
\text { firme dentro da máquina, } \\
\text { consequentemente } \\
\text { melhorando a fixação } \\
\text { da muda na terra. Além } \\
\text { de possibilitar que a } \\
\text { distância entre uma } \\
\text { planta e outra ficasse } \\
\text { padronizada }\end{array}$ & Não \\
\hline P.S & Fumicultor & $\begin{array}{l}\text { Dificuldade no transporte } \\
\text { do implemento } \\
\text { agrícola, já que a } \\
\text { lavoura não ficava } \\
\text { em sua propriedade, } \\
\text { além do implemento } \\
\text { ser transportado por } \\
\text { uma carroça que, ao } \\
\text { passar pelas vergas, } \\
\text { desmanchava o camaleão } \\
\text { já feito }\end{array}$ & $\begin{array}{l}\text { Disco adaptado } \\
\text { com rodas e } \\
\text { regulagem de } \\
\text { profundidade }\end{array}$ & $\begin{array}{l}\text { Melhora no momento } \\
\text { do transporte e as vergas } \\
\text { puderam ser feitas com } \\
\text { uma melhor qualidade }\end{array}$ & Não \\
\hline
\end{tabular}

Fonte: Elaborado pelos autores 
O agricultor/ferreiro Armindo Kittel (A.K.), residente no município de Sobradinho, ao ser questionado sobre o porquê da criação de uma enxada vazada, explica que sentia que a limpeza da lavoura utilizando a enxada disponibilizada no mercado tornava o trabalho muito desgastante, devido ao peso dela e à necessidade da utilização de movimentos repetitivos para realizar o trabalho, o que consequentemente prejudicava a saúde dos agricultores. Para que pudesse solucionar o problema existente em sua propriedade, ele resolveu criar uma enxada circular, que, ao invés da convencional que é toda fechada, possui uma abertura em seu centro que faz com que a terra passe pelo seu meio tornando-a mais leve para o trabalho, como explicado no trecho a seguir:

Pesquisadora: E como surgiu essa ideia?

A.K.: Simplesmente porque eu não gostava de capinar, eu achava muito pesada a enxada, então surgiu essa ideia de fazer isso aí. E uma, que ela passa terra pelo meio dela, ela não fica emborcando aquela terra, passa tudo pelo meio.

Pesquisador: Qual a diferença dela para uma enxada comum?

A.K.: A diferença dela para uma enxada comum é que a enxada comum é toda fechada. Essa, o meio dela é aberto, na hora que tu vai puxar terra, ela vai passar a terra no meio e não vai ficar tão pesada, e fica mais leviana em si mesma, pra tu trabalhar com ela.

Figura 2. Enxada circular.

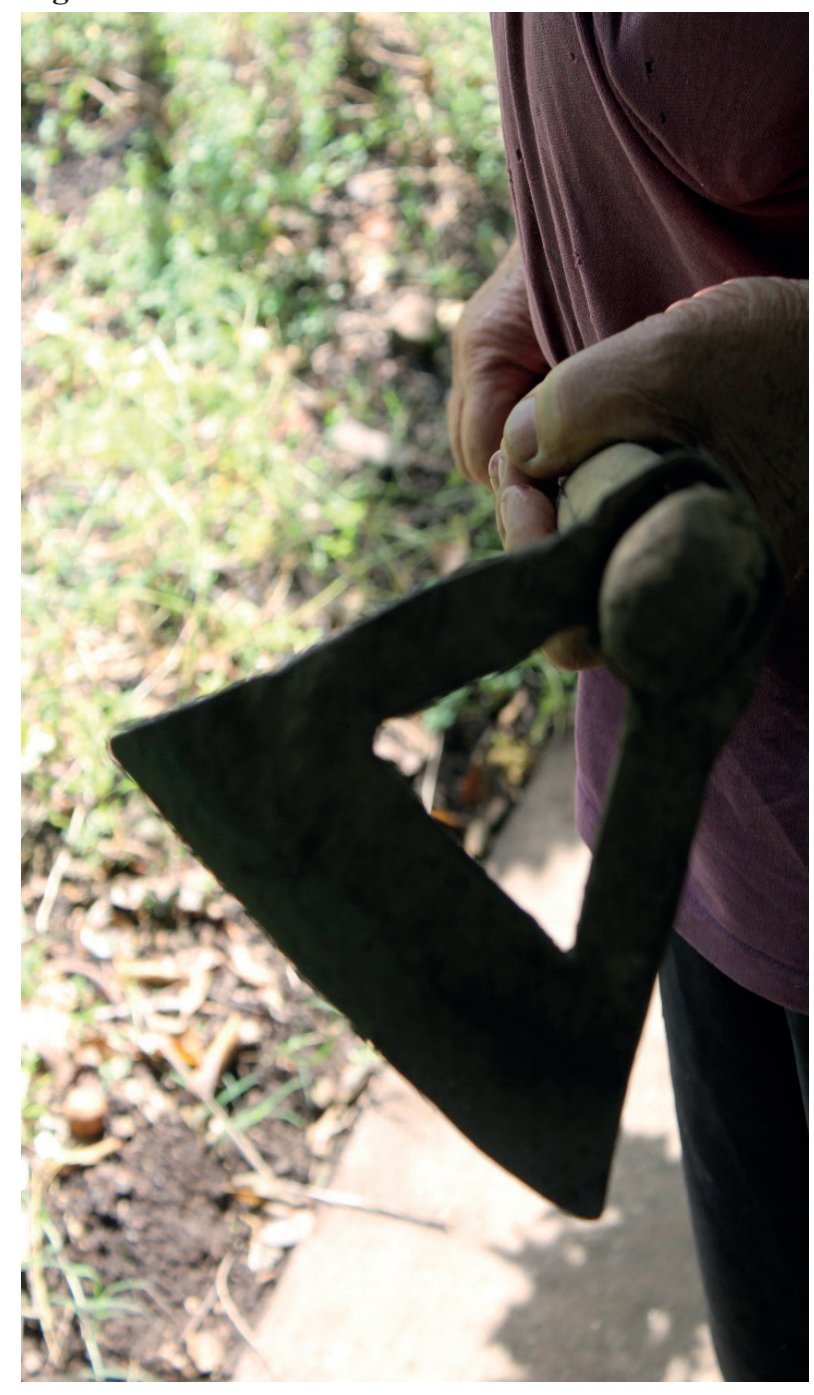

Foto: Alex Alexandre Mengel
A enxada circular foi criada, em um primeiro momento, para facilitar o trabalho da esposa de Armindo Kittel na lavoura. A esposa, ao utilizar a enxada na capina, gostou do resultado, despertando o interesse de outros agricultores da localidade. Essa criação deu tão certo que Armindo Kittel possui enxadas vazadas prontas para a comercialização em sua pequena propriedade.

Outro exemplo de solução tecnológica é o limpador de feijão que foi construído pelo agricultor Nercildo Bregon (N.B.), residente no município de Arroio do Tigre. Primeiramente, com o objetivo de reduzir o tempo gasto na secagem do feijão, que no sistema antigo, ainda utilizado atualmente, era exposto ao sol e seco naturalmente, o que acaba prejudicando sua secagem em dias de chuva, pois não pode ficar exposto, como ressaltado pelo agricultor:

Pesquisador: E o secador, o senhor fez por quê, por qual razão?

N.B.: Principal razão é que a gente colhe o feijão úmido, não existia secador particular, aí eu fiz o meu pequenininho. Ai tu não perde, vai (inaudível - 18:25) 
feijão no tempo de chuvarada, não tem como pôr no sol. E é um produto altamente perecível o feijão, se colher úmido, dá um jeito de secar ou perde.

A ideia para a construção do secador começou a ser elaborada a partir do momento em que o agricultor foi visitar um estande na Feira da Expoagro Afubra e viu um limpador de feijão em exposição. Com isso, o agricultor resolveu reutilizar uma antiga trilhadeira que estava desativada, pois o seu ventilador era grande o suficiente para ser utilizado na secagem do feijão. O agricultor, lembrando-se do que havia visto na feira, montou o seu próprio secador inspirando-se no modelo existente no mercado. A única diferença entre o modelo comercial e a sua solução tecnológica é que o ventilador que foi colocado no lugar da turbina e a estrutura do tijolo possibilitaram uma redução significativa nos gastos referentes à sua produção. O segundo motivo para a geração do seu próprio limpador de feijão é o alto preço dos limpadores disponíveis no mercado, que fica na faixa de 10 mil reais, possuindo um tamanho pequeno.

Pesquisador: Não existiam secadores no mercado?

N.B.: Ah, mas o preço.

Pesquisador: A dificuldade então é...

Pesquisadora: $\mathrm{O}$ preço.

N.B.: Quanto que tá um pequenininho de lata? Oito mil?

A.T.: Oito, dez mil.

Pesquisadora: Tudo isso?

A.T.: Sim!

Pesquisador: E quanto que o senhor gastou para fazer esse secador?

N.B.: Mas olha não deu mil reais. Mas ali foram 600 tijolos, dois sacos de cimento, meio metro de areia e a minha mão de obra.

O agricultor garante que a qualidade do seu limpador de feijão é a mesma da existente no limpador que é comercializado, chegando a funcionar durante 4 horas seguidas, precisando, contudo, ser desligado depois de passado esse período, para que haja o resfriamento do motor, para que mais tarde seja novamente ligado. A secagem do feijão realizada no sistema antigo consistia na colocação de uma lona grande com o feijão ao sol, a principal desvantagem era a qualidade do grão, que muitas vezes acabava torrando ou ficava com a casca solta. Com o limpador de feijão a qualidade melhorou e a mão de obra utilizada foi reduzida.

A solução tecnológica gerada pelo agricultor Paulo Severo (P.S.), residente no município de Santa Cruz do Sul, foi o disco adaptado com rodas e regulagem de profundidade, sendo ele adaptado de um disco antigo a boi, que já não funcionava tão bem. Depois de algumas melhorias, o agricultor resolveu adaptá-lo, já que seu problema era que quando ia preparar a lavoura, algumas delas em outra propriedade, distante de sua casa, precisava transportar o disco em uma carroça para que ao passar com o disco pela verga não fosse desmanchado o camaleão já feito na lavoura, o que causava muito desgaste físico e psicológico, além de ser mais difícil de transportar. $\mathrm{O}$ disco possui rodas e regulagem de profundidade, para que, no final da verga, por onde o disco passar, possa ser mais bem feito. Alguns agricultores da localidade pegam o disco adaptado emprestado para realizar o trabalho de discagem do solo. Nota-se que os agricultores em geral, quando vão 
construir as suas soluções tecnológicas, fazem a reutilização de materiais existentes na propriedade, utilizando ou adaptando antigos implementos ou máquinas agrícolas, e somente quando necessário realizam a compra de novos materiais para a fabricação.

Pesquisadora: E com o disco o que mudou, depois que o senhor começou a usá-lo?

P.S.: O disco, ele era um disco antigo a boi né, ele era e daí não funcionava como era para ser e se eu precisava transportar, tinha que carregar numa carroça pra levar de uma lavoura para outra né, porque tem as estradas e já pensando nisso e não destruir, não demolir o camaleão né, aí fiz o disco com roda e regulagem de profundidade, né.

Figura 3. Limpador de feijão.

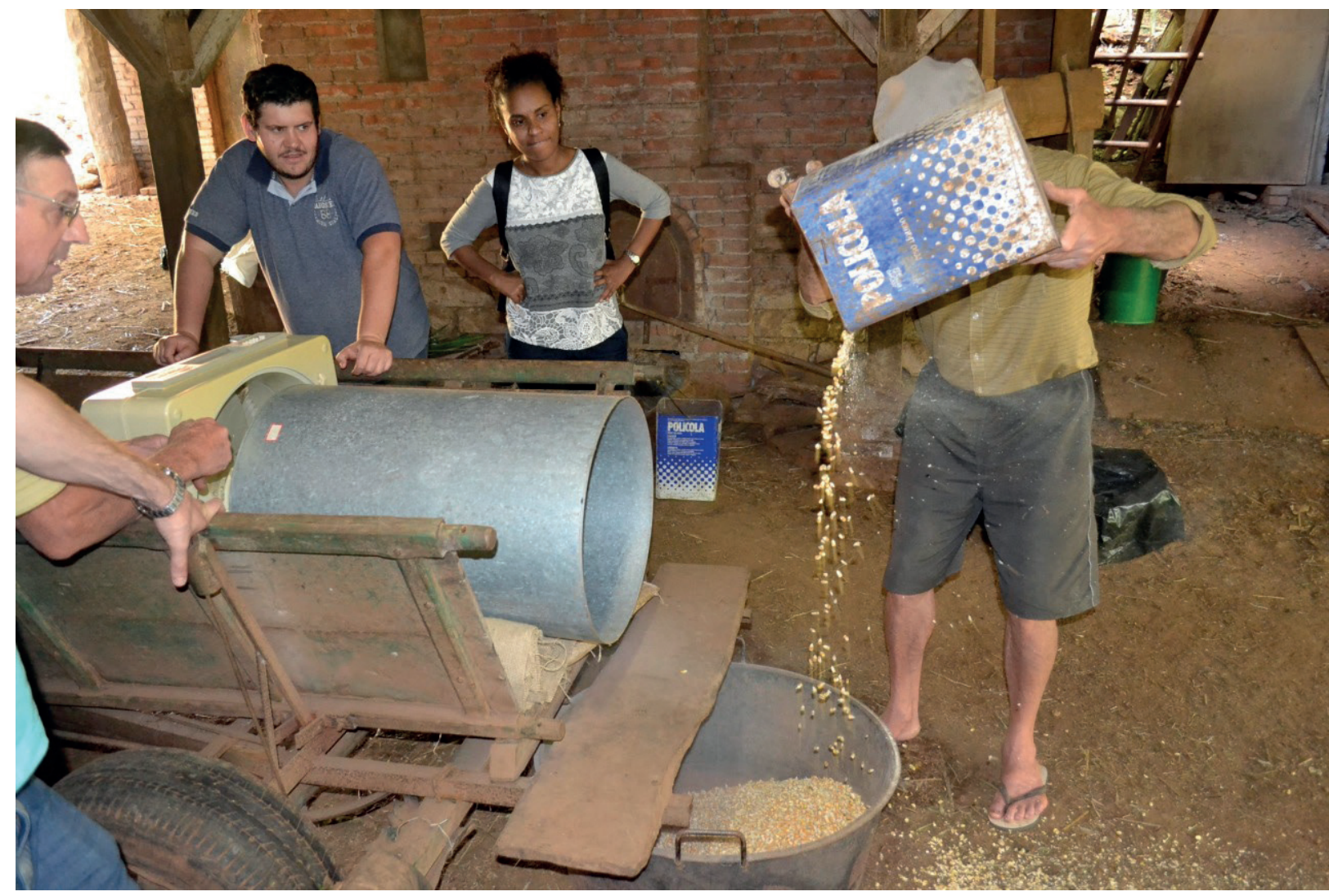

Foto: Alex Alexandre Mengel

Aproveitando o exemplo do agricultor Paulo Severo, outro importante aspecto a ser destacado quando se analisa a geração dessas soluções é a recorrente criação de mais de uma solução tecnológica pelos agricultores familiares, que, pensando em resolver seus problemas diários nas suas atividades produtivas, sentem a necessidade de pensar na geração de outras soluções tecnológicas, como é o caso do agricultor Paulo Severo, que, além do disco a boi adaptado com rodas e regulagem de profundidade, criou o desbacherador, que foi pensado a partir da preocupação do agricultor com sua saúde, porque um vizinho seu que trabalhou na colheita de fumo removendo o baixeiro manualmente teve um grave problema na coluna, por ter que ficar em uma posição desconfortável para remover as folhas da planta, por isso Paulo resolveu fazer uma adaptação, que torna o serviço mais demorado, porém não agride tanto a coluna como no sistema utilizado pela maioria dos agricultores. Sua principal função é eliminar a folha do pé, já que o baixeiro são 
as últimas folhas do pé que ficam em contato direito com a terra, e não são muito valorizadas na hora da compra pelas fumageiras.

Figura 4. Disco a boi adaptado com rodas e regulagem de profundidade.

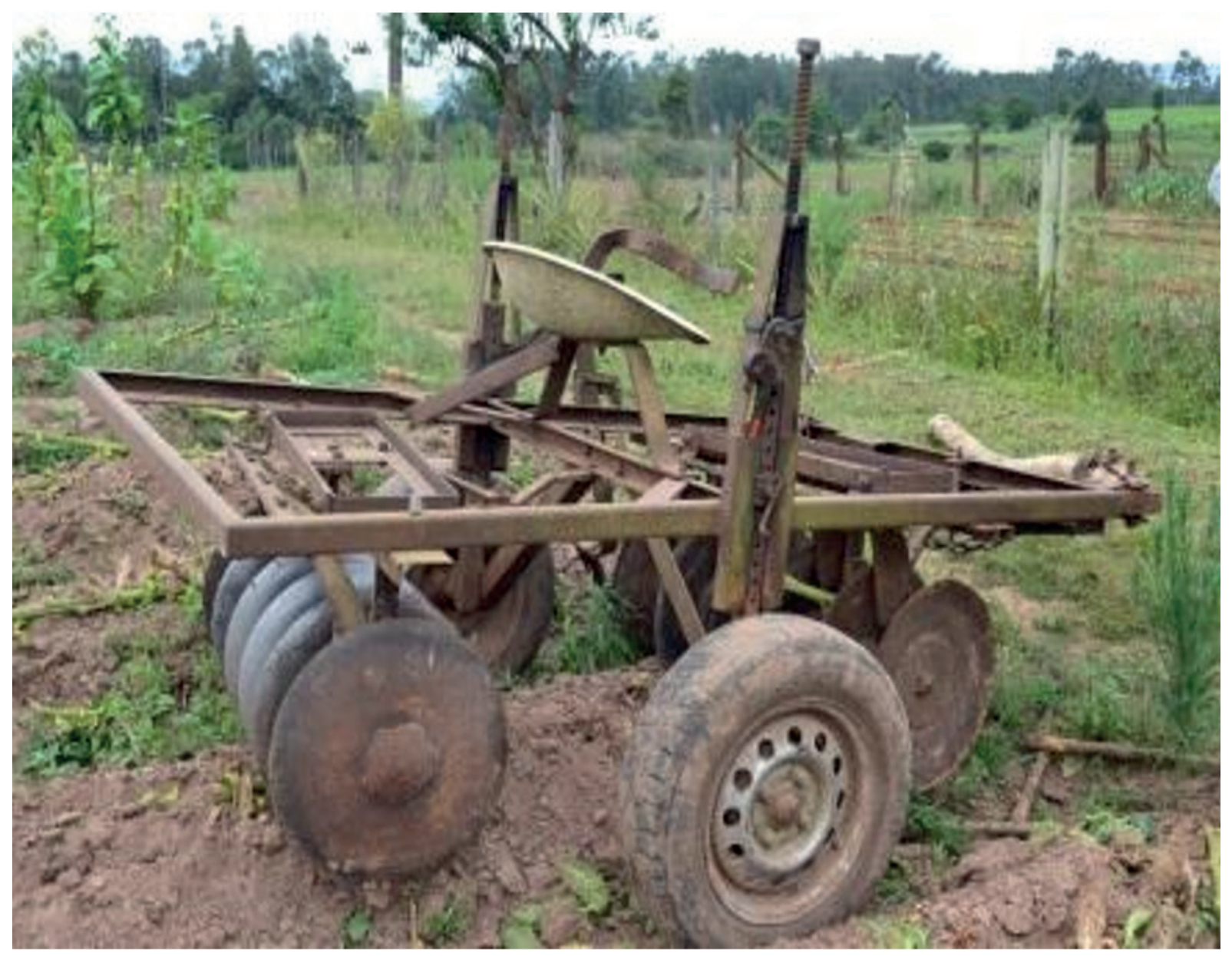

Foto: Alex Alexandre Mengel

Mesmo existindo algumas tecnologias disponíveis no mercado, elas geralmente, além de muito caras, não são adequadas para o trabalho existente na pequena propriedade onde o agricultor familiar se encontra, o que exige a geração dessas soluções tecnológicas para que o agricultor mantenha a sua manutenção como categoria. A geração de soluções tecnológicas é um elemento característico da categoria dos agricultores familiares, que encontram formas de resiliência e de manutenção no meio rural, o que permite a eles identificar e solucionar os problemas que dificultam o processo produtivo em sua propriedade, seja modificando um método produtivo, seja criando algum equipamento ou implemento agrícola.

O que se observou, nas entrevistas semiestruturadas realizadas com os agricultores familiares, foi que existe uma dinâmica na geração dessas soluções tecnológicas (Tabela 2), que é caracterizada geralmente pelas etapas a serem mostradas na Tabela 2.

Para exemplificar melhor a dinâmica evidenciada na Tabela 2, optou-se por selecionar uma das entrevistas para a realização da análise. Nesse caso, o agricultor chama-se Regis Quis (R.Q.) e mora no município de Santa Cruz do Sul, reconhecido como fumicultor. O agricultor, constatando o problema em sua atividade produtiva, resolveu realizar duas modificações na sua plantadeira 
de fumo. A primeira modificação foi pensada a partir de uma das empresas fumageiras de que o tabaco fosse plantado a uma distância média de $50 \mathrm{~cm}$, então, para melhorar sua eficiência na lavoura, ele projetou acoplar uma régua de metal com a ponta voltada para baixo em sua plantadeira, mas para isso seria necessário realizar a segunda modificação, que consistia em alterar o bico existente na máquina por onde as mudas de fumo saem, porque o bico da máquina convencional tinha um formato mais quadrado e comprido, o que deixava a muda solta dentro da máquina, dificultando sua saída. Além disso, dependendo do tipo de solo existente na propriedade e pelo fato de o bico convencional ter um material menos resistente, ao entrar em contato com a terra durante o plantio, acaba sendo danificado (Etapa 1).

Tabela 2. Dinâmica na geração das soluções tecnológicas no Vale do Rio Pardo, RS.

Dinâmica na geração das soluções tecnológicas

1) O agricultor tem um problema, pensa em formas de como resolvê-lo e se tem os equipamentos e materiais necessários para sua devida construção

2) Se não, ele procura um ferreiro, metalúrgico ou marceneiro presente na sua localidade, explica-lhe o problema existente e então os dois juntos pensam na melhor forma de resolvê-lo

3) A partir dessa conversação realizada, o ferreiro desenvolve a nova solução como lhe foi pedido pelo agricultor

4) O agricultor, depois que recebe a solução construída pelo ferreiro, marceneiro ou metalúrgico, testa o equipamento e se tiver algum problema e ele detiver os equipamentos necessários, ele mesmo modifica; se não, a solução retorna para o ferreiro

5) Depois do equipamento devidamente testado e aprovado, a dinâmica na geração das soluções tecnológicas se encerra. A solução tecnológica geralmente é emprestada para amigos e vizinhos, assim contribuindo para a disseminação desse novo modo de saber-fazer entre os agricultores locais

Fonte: Elaborado pelos autores

Refletindo sobre como seria essa modificação e os materiais que deveriam ser utilizados, o agricultor constatou que sozinho ele não conseguiria fazê-lo, então procurou o ferreiro em sua localidade. Depois de o encontrar e conversarem sobre qual seria a melhor forma de execução do seu projeto (Etapa 2), o ferreiro modificou o bico colocando uma lâmina de disco em sua ponta para deixá-la mais resistente e arredondada, acoplando também a régua na plantadeira depois de pronta (Etapa 3). Como o ferreiro não teve dificuldades em realizar a modificação, o agricultor não precisou retornar para fazer modificações na máquina (Etapa 4).

Depois de devidamente experimentada e aprovada, a plantadeira de fumo pôde ser utilizada normalmente. Foi constatada pelo agricultor uma melhora na distância entre as plantas, que não ficaram com grandes diferenças umas das outras, sendo que a qualidade e o tamanho do fumo também melhoraram, pois essa distância padronizada possibilitou o desenvolvimento das mudas. No caso do bico da plantadeira, a modificação possibilitou que a planta ficasse mais firme dentro da máquina, fazendo com que o torrão, ao entrar em contato com o solo, pegasse mais rápido, não chegando nem a murchar, tornando-se cada vez menos necessário realizar o replante posteriormente. Alguns agricultores da localidade também realizam essa modificação, melhorando o desenvolvimento dessa atividade produtiva (Etapa 5). 
Figura 5. Régua que marca a distância acoplada à plantadeira de fumo adaptada.

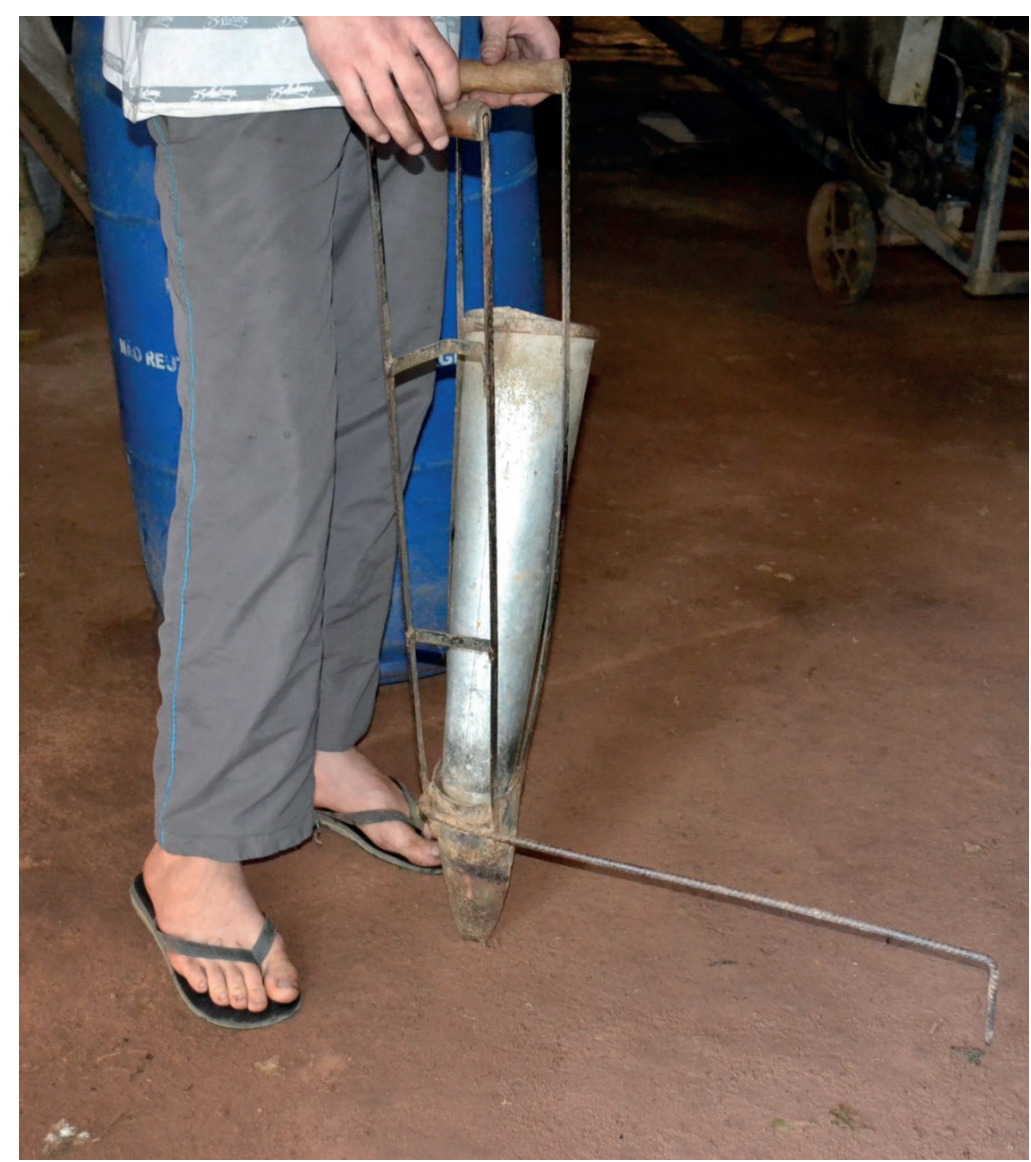

Foto: Alex Alexandre Mengel

Parte importante desse processo de geração de uma solução tecnológica é a proximidade com ferreiros/marceneiros/metalúrgicos ou, em alguns casos, o próprio agricultor também trabalha como ferreiro/metalúrgico/marceneiro. Essa situação acontece, principalmente, em razão de os agricultores não terem os equipamentos necessários que possibilitem a elaboração da sua solução, embora eles conheçam e entendam a técnica a ser produzida por seu novo equipamento. Assim, só conseguem resolver o problema com o auxílio prestado pelo ferreiro, geralmente da sua localidade, que possibilita a geração de uma nova solução tecnológica. Os ferreiros/marceneiros/metalúrgicos são parceiros dos agricultores nessa geração de soluções, pois estão presentes nas localidades e fazem parte do círculo de relações desses agricultores.

Quando se analisa o caso da agricultura familiar, ao observar todo o processo existente na concepção das soluções tecnológicas, nota-se que o que possibilita ao agricultor familiar detectar a necessidade da produção de uma solução tecnológica é o fato de que, ao mesmo tempo em que ele coordena o trabalho, também realiza todas as atividades existentes na sua propriedade. Isso fornece a ele uma visão ampla e privilegiada, fazendo com que identifique o problema existente e procure as melhores maneiras de solucioná-lo, gerando assim uma nova solução tecnológica.

Observa-se, nas soluções selecionadas para análise, que a trilogia da inovação schumpeteriana, marcada pela invenção, inovação e difusão, não se completa. Analisando cada uma das etapas, verificou-se que o processo de inovação, que se inicia pela invenção de algo que possua 
potencial para gerar impacto, poderá estar presente na ideia de solução tecnológica, pois elas surgem de um problema cotidiano e apresentam impacto na realidade do agricultor, uma vez que solucionam o problema para o qual foram produzidas. Além disso, destaca-se que as soluções tecnológicas criadas apresentam características que se afastam do conceito de inovação tecnológica de Schumpeter. As tarefas da trilogia schumpeteriana são executadas por agentes fixos; no caso da solução tecnológica, os agricultores familiares são os agentes que produzem todo o processo, em algumas situações conversam com outros agricultores ou buscam ferreiros, marceneiros; assim, o agricultor, na maioria das vezes, domina o processo de produção da solução tecnológica. Dessa forma, o conceito de inovação schumpeteriano não se adapta à compreensão das técnicas, dos produtos e dos processos criados pelos agricultores familiares.

Para além da geração de novas técnicas, tecnologias, processos ou produtos, soluções tecnológicas evidenciam a resiliência existente na agricultura familiar como categoria, pois os agricultores familiares, apesar de estarem sujeitos a um mercado cada vez mais competitivo e excludente, conseguem se adaptar e elaborar estratégias que garantam a sua sobrevivência, estabelecendo relações com os atores de sua localidade, reutilizando materiais e aproximando o seu vínculo com a natureza, tornando as soluções tecnológicas algo característico e fundamental ao ser agricultor.

\section{Conclusão}

Apesar de o conceito de inovação ser amplo e ter grande flexibilidade, aliado ao fato de o conceito de produção de novidades se assemelhar muito ao de solução tecnológica, ambos não são utilizáveis no contexto em que os agricultores familiares do Vale do Rio Pardo estão inseridos. Dessa forma, o conceito de soluções tecnológicas foi o que melhor se adaptou à realidade dos agricultores e a seu cotidiano, estando de acordo com o foco desta pesquisa.

A geração de soluções tecnológicas é um elemento característico da categoria dos agricultores familiares, principalmente porque o agricultor está presente e realiza todas as atividades produtivas de sua propriedade, o que permite a eles identificar e solucionar os problemas que dificultam o seu processo produtivo, seja modificando um método produtivo ou criando um equipamento ou implemento agrícola.

Mesmo existindo algumas tecnologias disponíveis no mercado, geralmente elas, além de caras, não são adequadas para a pequena propriedade onde o agricultor familiar se encontra, o que exige a geração dessas soluções tecnológicas. Essas soluções tecnológicas são entendidas como novas técnicas ou tecnologias que, ao serem desenvolvidas e inseridas no processo produtivo, modificam a maneira de os agricultores se relacionarem com a natureza, ou seja, modificam sua maneira de trabalhar e de viver.

O principal desafio da pesquisa é fazer com que o conhecimento gerado por esses agricultores chegue até sua categoria social, saindo de uma perspectiva local em que as soluções tecnológicas estão inseridas para serem amplamente utilizadas e divulgadas. Assim, uma possibilidade de publicização é a incubação de algumas das soluções tecnológicas encontradas pela equipe do projeto na Incubadora Tecnológica (ITUNISC), localizada na Unisc, divulgando no âmbito acadêmico e social o conhecimento produzido pelos agricultores familiares do Vale do Rio Pardo 
e garantindo ao agricultor-inventor, além de seu reconhecimento, quiçá o patenteamento da inovação produzida.

\section{Referências}

AREND, S. et al. Observando o desenvolvimento regional do Vale do Rio Pardo: notas sobre as dinâmicas econômicas recentes. Barbarói, Santa Cruz do Sul, n. 54, p. 234-257, jul./dez. 2019.

BANCONACIONALDE DESENVOLVIMENTOECONÔMICOESOCIAL-BNDES. BNDES Soluções Tecnológicas. O que é uma solução tecnológica? BNDES - O Banco Nacional do Desenvolvimento. Brasília, DF, 2018.

DEPONTI, C. Inovações Schumpeterianas e soluções tecnológicas para a agricultura familiar no Vale do Rio Pardo-RS-Brasil: uma análise das contradições. Trabalho apresentado no 32. Congreso Internacional ALAS Peru, 2019.

FERGUSON, P. R. Industrial economics: issues and perspectives. London: Macmillan Education UK, 1988. $216 \mathrm{p}$.

GARCIA, R.; CALANTONE, R. A critical look at technological innovation typology and innovativeness terminology: a literature review. The Journal of Product Innovation Management, v. 19, n. 2, p. 110$132,2002$.

KARNOPP, E. Tendências de desenvolvimento da agricultura familiar: uma análise regional. RDE Revista de Desenvolvimento Econômico, v. 14, p. 99-110, 2012.

KIYOTA, N. et al. A agroindústria familiar e a produção de novidades no desenvolvimento rural: uma análise comparativa entre Sul e Nordeste do Brasil. In: SCHNEIDER, S. et al. (Org.). Sementes e brotos da transição: inovação, poder e desenvolvimento em áreas rurais do Brasil. Porto Alegre: UFRGS, 2014. v. 1, p. 71-90.

LONG, N. Development sociology: actor perspectives. London: Routledge, 2001.

MENGEL, A. A. et al. Agricultura familiar e soluções tecnológicas - agentes locais como protagonistas na geração de conhecimento. Redes - Revista do Desenvolvimento Regional, Santa Cruz do Sul, v. 25, n. 1, p. 84-103, jan./abr. 2020.

OLIVEIRA, D.; ARAUJO, J. P. Produção de novidades na transição agroecológica. In: SCHNEIDER, S. et al. (Org.). Sementes e brotos da transição: inovação, poder e desenvolvimento em áreas rurais do Brasil. Porto Alegre: UFRGS, 2014. v. 1, p. 165-192.

OLIVEIRA, D. et al. A produção de novidades: como os agricultores fazem para fazer diferente?. In: SCHNEIDER, S.; GAZOLLA, M. (Org.). Os atores do desenvolvimento rural. Porto Alegre: Editora da UFRGS, 2011. v. 1, p. 91-113.

PINTO, A. V. O conceito de tecnologia. Rio de Janeiro: Contraponto, 2005. v. 1.

PLOEG, J. D. van der. et al. On Regimes, Novelties, Niches and Co-Production. In: PLOEG, J. D. van der; WISKERKE, J. S. C. (Ed.). Seeds of transition: essays on novelty production, niches and regimes in agriculture. Wageningen: Royal Van Gorcum, 2004. p. 1-28.

SCHNEIDER, S. et al. (Org.). Sementes e brotos da transição: inovação, poder e desenvolvimento em áreas rurais do Brasil. Porto Alegre: Editora da UFRGS, 2014. 
SCHUMPETER, J. A. A teoria do desenvolvimento econômico: uma investigação sobre lucros, capital, crédito, juro e o ciclo econômico. São Paulo: Nova Cultural, 1982.

STONEMAN, P. Handbook of the economics of innovation and technological change. [s.1.]: Blackwell, 1995. $600 \mathrm{p}$. 
